\title{
FINANÇAS PESSOAIS: UMA ANÁLISE SOB A ÓTICA DAS PRODUÇÕES CIENTÍFICAS DE 2012 A 2017
}

Andréia do Prado Bueno ${ }^{1}$ Larissa de Lima Trindade ${ }^{2}$

Resumo: O presente estudo ocupou-se da análise da produção científica sobre o tema finanças pessoais, ao propor uma busca das produções disponibilizadas no Portal Periódicos da Capes e a sintetização dos resultados, por intermédio da metodologia da revisão integrativa. Os resultados contemplaram 17 publicações, que foram integradas em quatro categorias, sendo a categoria conhecimento financeiro a mais representativa. A sintetização e integração dos resultados possibilita a observação das variáveis que influenciam o comportamento e conhecimento financeiro dos indivíduos, além de fomentar o debate da importância da alfabetização financeira da população brasileira.

Palavras-chave: Finanças Pessoais; Educação Financeira; Conhecimento Financeiro.

\section{PERSONAL FINANCE: AN ANALYSIS FROM THE SCIENTIFIC PRODUCTION VIEWS FROM 2012 TO 2017}

\begin{abstract}
The present study focused on the analysis of scientific production on the subject of personal finances, proposing a search of the productions made available in Capes' Portal Periodical and synthesizing the results, through the methodology of the integrative review. The results included 17 publications, which were integrated into four categories, with the financial knowledge category being the most representative. Synthesizing and integrating the results enables the observation of the variables that influence the individuals' financial behavior and knowledge, as well as fostering the debate about the importance of financial literacy for the Brazilian population.
\end{abstract}

Keywords: Personal Finance; Financial Education; Financial Knowledge.

\section{FINANZAS PERSONALES: UN ANÁLISIS DESDE LA PERSPECTIVA DE LAS PRODUCCIONES CIENTÍFICAS DE 2012 A 2017}

Resumen: El presente estudio se ocupó del análisis de la producción científica sobre el tema finanzas personales, al proponer una búsqueda de las producciones disponible en el Portal Periódicos de la Capes y la sintetización de los resultados, por intermedio de la metodología de la revisión integrativa. Los resultados contemplaron 17 publicaciones, que fueron integradas en cuatro categorías, siendo la categoría conocimiento financiero la más representativa. La sintetización e integración de los resultados posibilita la observación de las variables que influencian el comportamiento y conocimiento financiero de los individuos, además de fomentar el debate de la importancia de la alfabetización financiera de la población brasileña.

Palabras llave: Finanzas Personales; Educación Financiera; Conocimiento Financiero.

\section{Introdução}

A gama de produtos financeiros no Brasil tem crescido nas últimas décadas, graças à estabilidade financeira, ao controle inflacionário e a criação do Plano Real desfrutada no início da década de 90. A abertura de crédito concedida às classes sociais inferiorizadas economicamente, ocorrida no início dos anos 2000, criou um novo mercado consumidor e como

\footnotetext{
${ }^{1}$ Bacharela em Administração pela Universidade Federal da Fronteira Sul (UFFS); Pós-Graduada em Gestão Pública na Educação Profissional e Tecnológica, pelo Instituto Federal de Santa Catarina (IFSC). Servidora Pública Técnica Administrativa na UFFS. E-mail: anndreia21@ gmail.com

${ }^{2}$ Doutora em Ciência Humanas pelo Programa de Pós-Graduação Interdisciplinar em Ciências Humanas da Universidade Federal de Santa Catarina; Professora Adjunta da Universidade Federal da Fronteira Sul, Campus Chapecó-SC. E-mail:larissa.trindade@uffs.edu.br
} 
resultado a ascensão econômica destas classes, principalmente da classe C, que em 2010 "tornou-se a maior em número absoluto de pessoas na pirâmide social brasileira" (VENTURA, 2010, p. 4).

O desenvolvimento de uma região e/ou nação depende de incontáveis fatores, como da saúde financeira das pessoas. Do mesmo modo, o desenvolvimento socioeconômico é influenciado diretamente pela qualidade de vida dos cidadãos, que só é alcançada quando os indivíduos conseguem ultrapassar suas dificuldades com relação ao dinheiro, evoluindo para uma cultura de poupança e como fruto desse conhecimento atingir a evolução financeira. Essa relação promove escolhas conscientes na compra e contribui para o crescimento e sustentabilidade das empresas e do ambiente macroeconômico (SAVOIA, SAITO, SANTANA; OLIVATO, SOUSA, 2007).

Enquanto a educação financeira promove consciência no trato com as finanças pessoais, a falta dela pode acarretar inúmeros problemas, como o endividamento. A Serasa Experian, através de uma pesquisa realizada em agosto de 2019, por exemplo, apontou que a inadimplência atingiu mais de 63 milhões de brasileiros e 31,20\% do total de jovens na faixa de 18 a 25 anos. Esses números revelam a falta de consciência financeira e reflexos de uma sociedade de consumo (TRINDADE, 2009).

É evidente que a ampla oscilação na economia brasileira causa insegurança e grande parte da população não está preparada para situações adversas, pois não são educados financeiramente ao longo da vida. Outrossim, é notório que as políticas públicas nesse sentido são falhas e insuficientes, o que gera, consequentemente, despreparo da população e confusão ou até mesmo fracasso na gestão financeira pessoal (LUCI, et al., 2006; SAITO; SANTANA, 2007; SAVOIA; CLAUDINO; NUNES; SILVA, 2009).

Através dessas informações, é possível perceber que o Estado não proporciona educação financeira no mesmo ritmo em que concede crédito e impulsiona o consumo da sociedade brasileira. Possivelmente, esse conhecimento deficitário acerca de finanças pessoais dos brasileiros se deve principalmente ao cenário econômico vivido durante as décadas de 60 a 90 , onde havia altas taxas inflacionárias, instabilidade financeira e escassez de produtos financeiros e de investimentos (NUNES, 2006; ZERRENER, 2007; MATTA, 2007; FERNANDES, CANDIDO, 2014). E infelizmente quem mais sofre com o endividamento são aquelas pessoas que possuem renda e escolaridade mais baixas. (ZERRENNER, 2007; CLAUDINO, NUNES, SILVA, 2009; VIEIRA, FLORES, CAMPARA, 2015).

Contudo, as últimas ações do governo federal demonstram a recente preocupação do Estado com o tema. A $3^{\text {a }}$ edição da Base Nacional Comum Curricular, incorpora aos sistemas e redes de ensino a abordagem de "temas contemporâneos que afetam a vida humana em escala 
local, regional e global, preferencial de forma transversal e integradora" (MINISTÉRIO DA EDUCAÇÃO, 2014, p. 13). Educação para o consumo e educação financeira e fiscal são alguns destes temas. Antes disso, em 2010, já atento a esses aspectos, o Governo Federal criou a Estratégia Nacional de Educação Financeira (ENEF) lançada pelo Decreto no 7.397. O programa foi criado para promover a educação financeira e previdenciária em razão do impulso às políticas de inclusão social no País. A proposta é fortalecer a cidadania, oferecendo aos brasileiros conceitos sobre previdência e sistema financeiro (MINISTÉRIO DA EDUCAÇÃO, 2014).

Diante do exposto, a presente pesquisa tem como objetivo analisar a forma como o conhecimento dos brasileiros acerca de finanças pessoais está sendo abordado nas produções científicas mais recentes, disponibilizadas no Portal Periódico da Capes. A metodologia empregada foi a da revisão integrativa, que permite a integração dos manuscritos obtidos.

Este artigo está estruturado em quatro seções considerando a introdução, onde: a seção dois apresenta o método empregado na pesquisa, a terceira seção discute os resultados alcançados e a última expõe as considerações finais.

\section{Metodologia}

Para responder a indagação do estudo, utilizou-se a metodologia da revisão integrativa, que busca reunir e sintetizar os resultados de pesquisas sobre determinado tema, de maneira sistemática e ordenada, "contribuindo para o aprofundamento do conhecimento do tema investigado" (MENDES; SILVEIRA; GALVÃO, 2008, p. 2).

A revisão integrativa do estudo ocorreu no portal Periódicos da Coordenação de Aperfeiçoamento de Pessoal de Nível Superior (Capes). O portal Periódicos da Capes foi escolhido devido a sua relevância no ambiente acadêmico, tendo em vista que é um importante mecanismo de democratização de acesso a informações científicas em todo o Brasil.

A busca ocorreu observando as seguintes etapas: i) definição da pergunta de pesquisa; ii) definição dos critérios de inclusão e exclusão da pesquisa; iii) extração de informações dos estudos; iv) formação do banco de dados e discussão dos resultados. Após a definição da pergunta de pesquisa ( $1^{\text {a }}$ etapa), determinou-se a busca pelos seguintes descritores: finanças pessoais, educação financeira e conhecimento financeiro.

Durante a coleta, foram excluídos os trabalhos duplicados e aqueles que porventura após a leitura dos resumos não estavam relacionados ao problema de pesquisa. A leitura dos resumos resultou em 34 manuscritos sobre o tema, sendo que a análise completa desses artigos produziu um resultado final de 17 artigos, conforme disposto no Quadro 1. 
FAZ CIÊNCIA, VOL. 22, N. 35, JAN/JUN DE 2020 - P. 139-159

Quadro 1 - Resultado final de artigos coletados segundo a metodologia da revisão integrativa.

\begin{tabular}{|c|c|c|c|c|}
\hline Descritor* & $\begin{array}{l}\text { Total de artigos } \\
\text { pesquisados, } \\
\text { segundo o Portal } \\
\text { Periódicos da } \\
\text { Capes, sem } \\
\text { nenhum critério } \\
\text { de inclusão.* }\end{array}$ & $\begin{array}{l}\text { Total de artigos } \\
\text { após a inclusão } \\
\text { dos seguintes } \\
\text { critérios: } \\
\text { 1) artigos em } \\
\text { todos os idiomas } \\
\text { e solicitados } \\
\text { exatamente } \\
\text { segundo suas } \\
\text { palavras; } \\
\text { 2)publicados nos } \\
\text { últimos } 5 \text { anos.* }\end{array}$ & $\begin{array}{l}\text { Total de artigos } \\
\text { após os seguintes } \\
\text { critérios: } \\
\text { 1) artigos que } \\
\text { abordassem em seu } \\
\text { resumo pelo menos } \\
\text { um aspecto } \\
\text { relacionado ao } \\
\text { tema e que não } \\
\text { fossem repetidos; } \\
\text { 2) artigos } \\
\text { disponíveis em } \\
\text { português; } \\
\text { 3) disponíveis } \\
\text { eletrônica e } \\
\text { gratuitamente no } \\
\text { portal da Capes ou } \\
\text { em páginas } \\
\text { direcionadas. * }\end{array}$ & $\begin{array}{l}\text { Total de artigos } \\
\text { após a leitura } \\
\text { completa do } \\
\text { artigo, segundo o } \\
\text { seguinte critério } \\
\text { de inclusão: } \\
\text { 4) artigos que } \\
\text { abordassem pelo } \\
\text { menos um } \\
\text { aspecto } \\
\text { relacionado ao } \\
\text { tema. }\end{array}$ \\
\hline $\begin{array}{l}\text { Finanças } \\
\text { Pessoais }\end{array}$ & 574 & 36 & 9 & 5 \\
\hline $\begin{array}{l}\text { Educação } \\
\text { Financeira }\end{array}$ & 3.425 & 71 & 15 & 5 \\
\hline $\begin{array}{l}\text { Conheciment } \\
\text { o financeiro }\end{array}$ & 6.543 & 16 & 9 & 7 \\
\hline Total & 10.542 & 123 & 34 & 17 \\
\hline
\end{tabular}

Fonte: as autoras.

*Etapas 1, 2, 3 e 4 realizadas nos dias 04 a 06 de novembro de 2017.

Após a leitura completa e seleção dos artigos e a fim de criar um documento que descrevesse algumas características dos artigos selecionados, houve o registro em formulário próprio com a descrição mais detalhada de cada um, conforme ilustra o Quadro 2. 
Quadro 2 - Resultado final de artigos coletados segundo a metodologia da revisão integrativa.

\begin{tabular}{|c|c|c|c|c|c|}
\hline Artigo & Descritor & Autor (es)/Ano & Periódico & $\begin{array}{l}\text { Qualis do } \\
\text { Periódico }\end{array}$ & Métodos \\
\hline Artigo 1 & $\begin{array}{l}\text { Finanças } \\
\text { Pessoais }\end{array}$ & $\begin{array}{l}\text { Moreira e Carvalho, } \\
2013\end{array}$ & $\begin{array}{l}\text { Revista de Gestão, } \\
\text { Finanças e } \\
\text { Contabilidade }\end{array}$ & $\mathrm{B} 2$ & $\begin{array}{l}\text { Pesquisa exploratória e } \\
\text { descritiva; pesquisa de } \\
\text { campo; } \quad \text { questionário } \\
\text { estruturado. }\end{array}$ \\
\hline Artigo 2 & $\begin{array}{l}\text { Finanças } \\
\text { Pessoais }\end{array}$ & $\begin{array}{l}\text { Flores; Vieira, } \\
\text { Coronel;2012 }\end{array}$ & $\begin{array}{l}\text { Faces: Revista de } \\
\text { Administração }\end{array}$ & B2 & $\begin{array}{l}\text { Pesquisa aplicada: } \\
\text { quantitativa e descritiva; } \\
\text { survey; questionário. }\end{array}$ \\
\hline Artigo 3 & $\begin{array}{l}\text { Finanças } \\
\text { Pessoais }\end{array}$ & $\begin{array}{l}\text { Silva; Silva Neto; } \\
\text { Araújo, } 2017\end{array}$ & $\begin{array}{l}\text { Revista Evidenciação } \\
\text { Contábil e Finanças }\end{array}$ & B3 & $\begin{array}{l}\text { Abordagem quantitativa; } \\
\text { Questionário estruturado. }\end{array}$ \\
\hline Artigo 4 & $\begin{array}{l}\text { Finanças } \\
\text { Pessoais }\end{array}$ & $\begin{array}{l}\text { Campara; Vieira; } \\
\text { Flores Costa; Fraga, } \\
2016\end{array}$ & $\begin{array}{l}\text { REMARK: Revista } \\
\text { Brasileira de } \\
\text { Marketing }\end{array}$ & B1 & $\begin{array}{l}\text { Abordagem qualitativa; } \\
\text { entrevista. }\end{array}$ \\
\hline Artigo 5 & $\begin{array}{l}\text { Finanças } \\
\text { Pessoais; }\end{array}$ & $\begin{array}{c}\text { Figueira; Pereira, } \\
2014 .\end{array}$ & $\begin{array}{l}\text { REMARK: Revista } \\
\text { Brasileira de } \\
\text { Marketing } \\
\end{array}$ & B1 & $\begin{array}{l}\text { Abordagem quantitativa; } \\
\text { questionários. }\end{array}$ \\
\hline Artigo 6 & $\begin{array}{l}\text { Educação } \\
\text { Financeira }\end{array}$ & $\begin{array}{c}\text { Cunha; Laudares, } \\
2017\end{array}$ & $\begin{array}{c}\text { BOLEMA: Boletim } \\
\text { de Educação } \\
\text { Matemática } \\
\end{array}$ & A1 & Não informou. \\
\hline Artigo 7 & $\begin{array}{l}\text { Educação } \\
\text { Financeira }\end{array}$ & Destefani, 2015 & Eventos Pedagógicos & B4 & $\begin{array}{l}\text { Abordagem qualitativa; } \\
\text { estudo de caso; } \\
\text { questionários. }\end{array}$ \\
\hline Artigo 8 & $\begin{array}{l}\text { Educação } \\
\text { financeira }\end{array}$ & $\begin{array}{l}\text { Vieira; Valcanover; } \\
\text { Brutti; Trindade; } \\
\text { Kegler; } 2017\end{array}$ & $\begin{array}{c}\text { Revista Ibero- } \\
\text { Americana de } \\
\text { Estudos em Educação }\end{array}$ & B3 & $\begin{array}{l}\text { Questionário aplicado em } \\
\text { sala de aula durante o } \\
\text { curso proposto. }\end{array}$ \\
\hline Artigo 9 & $\begin{array}{l}\text { Educação } \\
\text { financeira }\end{array}$ & $\begin{array}{l}\text { Scolari; Grando. } \\
2016\end{array}$ & $\begin{array}{c}\text { Educação Matemática } \\
\text { Pesquisa }\end{array}$ & B3 & $\begin{array}{l}\text { Abordagem qualitativa; } \\
\text { proposta pedagógica no } \\
\text { ensino fundamental. }\end{array}$ \\
\hline Artigo 10 & $\begin{array}{l}\text { Educação } \\
\text { financeira }\end{array}$ & $\begin{array}{l}\text { Osinski; Pereira; } \\
\text { Neis; Morais Neto, } \\
2013 \\
\end{array}$ & $\begin{array}{l}\text { Revista de Ciências } \\
\text { da Administração }\end{array}$ & B1 & $\begin{array}{l}\text { Survey; } \quad \text { questionário } \\
\text { estruturado. }\end{array}$ \\
\hline Artigo 11 & $\begin{array}{l}\text { Conhecim } \\
\text { ento } \\
\text { financeiro }\end{array}$ & $\begin{array}{l}\text { Costa; Miranda, } \\
2013\end{array}$ & $\begin{array}{c}\text { Revista de Gestão, } \\
\text { Finanças e } \\
\text { Contabilidade } \\
\end{array}$ & B2 & $\begin{array}{l}\text { Quantitativa, } \begin{array}{r}\text { survey, } \\
\text { questionário } \\
\text { fechado; } \\
\text { hipóteses. }\end{array} \\
\end{array}$ \\
\hline Artigo 12 & $\begin{array}{l}\text { Conhecim } \\
\text { ento } \\
\text { financeiro } \\
\end{array}$ & $\begin{array}{l}\text { Potrich; Vieira; } \\
\text { Ceretta;, } 2013\end{array}$ & $\begin{array}{c}\text { Revista Eletrônica de } \\
\text { Ciência } \\
\text { Administrativa } \\
\end{array}$ & B1 & Questionários. \\
\hline Artigo 13 & $\begin{array}{l}\text { Conhecim } \\
\text { ento } \\
\text { financeiro }\end{array}$ & $\begin{array}{l}\text { Potrich; Vieira; } \\
\text { Kirch, } 2015\end{array}$ & $\begin{array}{c}\text { Revista Contabilidade } \\
\text { \& Finanças }\end{array}$ & A2 & $\begin{array}{l}\text { Abordagem qualitativa e } \\
\text { quantitativa; Hipóteses, } \\
\text { questionários. }\end{array}$ \\
\hline Artigo 14 & $\begin{array}{l}\text { Conhecim } \\
\text { ento } \\
\text { financeiro }\end{array}$ & $\begin{array}{c}\text { De Oliveira Silva } e t \\
a l ., 2017\end{array}$ & $\begin{array}{l}\text { Revista de Gestão, } \\
\text { Finanças e } \\
\text { Contabilidade }\end{array}$ & B2 & $\begin{array}{ll}\text { Abordagem } & \text { quantitativa; } \\
\text { Survey; } & \text { questionário } \\
\text { estruturado. } & \end{array}$ \\
\hline Artigo 15 & $\begin{array}{l}\text { Conhecim } \\
\text { ento } \\
\text { financeiro }\end{array}$ & $\begin{array}{l}\text { Silva e Silva; } \\
\text { Escorisa, } 2017\end{array}$ & $\begin{array}{c}\text { Educação Matemática } \\
\text { Pesquisa }\end{array}$ & B3 & $\begin{array}{l}\text { Minicurso com conteúdo } \\
\text { introdutório de gestão de } \\
\text { finanças pessoais com } \\
\text { alunos do Ensino } \\
\text { Fundamental. }\end{array}$ \\
\hline Artigo 16 & $\begin{array}{l}\text { Conhecim } \\
\text { ento } \\
\text { financeiro }\end{array}$ & $\begin{array}{l}\text { Medeiros; Lopes, } \\
2014\end{array}$ & $\begin{array}{l}\text { Revista Eletrônica de } \\
\text { Estratégia e Negócios }\end{array}$ & B2 & $\begin{array}{ll}\text { Abordagem } & \text { quantitativa; } \\
\text { descritiva; } & \text { questionário } \\
\text { fechado. } & \\
\end{array}$ \\
\hline Artigo 17 & $\begin{array}{l}\text { Conhecim } \\
\text { ento } \\
\text { financeiro } \\
\end{array}$ & $\begin{array}{l}\text { Roquete; Laureano; } \\
\text { Botelho } 2014\end{array}$ & $\begin{array}{c}\text { Tourism \& } \\
\text { Management Studies }\end{array}$ & B1 & Hipóteses; Questionários. \\
\hline
\end{tabular}

Fonte: as autoras. 
Observa-se a, partir do Quadro 2 que dos dezessete (17) artigos selecionados, onze (11) foram publicados em revistas da área de Ciências Sociais Aplicadas, visto que a Revista de Gestão, Finanças e Contabilidade, avaliada como B2, foi a que contemplou mais artigos com três (3) publicações no total. Quanto a avaliação das revistas, o Qualis B1 e B2 foram os que se destacaram, com cinco (5) publicações cada.

O descritor conhecimento financeiro se mostrou mais significativo para esta pesquisa, pois contemplou quase todas as pesquisas de avaliação de níveis de conhecimento financeiro dos indivíduos, onde três (3) delas foram produzidas com estudantes universitários. A abordagem quantitativa foi a que mais se evidenciou, foram abrangidas sete (7) pesquisas com esta metodologia. Quanto ao método de coleta de dados, o questionário foi utilizado por treze (13) dos dezessete (17) artigos analisados.

\section{Discussão dos Resultados}

A leitura e análise dos artigos permitiram o agrupamento dos estudos em quatro categorias, conforme prevê a metodologia de revisão integrativa, foram elas: perfil e variáveis em finanças pessoais; comportamento dos inadimplentes; mensuração do conhecimento financeiro e educação financeira na infância.

A primeira categoria, perfil e variáveis em finanças pessoais, contempla sete (7) manuscritos, representando $41,18 \%$ do total de artigos classificados. Todos, em algum momento, tratam de perfil e/ou comportamento financeiro dos indivíduos.

O primeiro artigo, escrito por Moreira e Carvalho (2013) investiga o perfil das finanças pessoais dos professores da rede municipal de ensino de Campo Formosa, no estado da Bahia. Os autores partem do pressuposto da falta de conscientização financeira dos grupos familiares, visto que a educação financeira não nas é abordada de forma profunda escolas, "haja vista que os próprios professores têm dificuldade de controlar suas finanças" (MOREIRA; CARVALHO, 2013, p. 3). Nesse sentido os autores apontam a necessidade do tema ser ampliado no âmbito escolar e refletem aspectos sobre o crédito, dinheiro, consumismo, alienação, endividamento e inadimplência na economia brasileira.

O estudo buscou informações quanto a renda e gastos dos professores, a relação entre essas variáveis, percentual de dívidas, opções de crédito utilizadas e orçamento familiar. Os dados obtidos apontaram que é necessário desenvolver projetos de aperfeiçoamento na formação dos docentes quanto a educação financeira, antes de implementar o tema nas escolas, pois $71 \%$ dos professores possuem "hábitos financeiros que convergem para uma situação de inadimplência” (MOREIRA; CARVALHO, 2013, p. 11). Grande parte dos entrevistados 
afirmaram que possuem uma renda complementar. A pesquisa também revelou que os professores possuem o hábito imediatista e impulsivo de consumir, geralmente usando o crédito para pagar, refletindo a falta de orçamento familiar da maioria dos entrevistados (57\%).

Já Flores, Vieira e Coronel (2012) ao analisar a influência de fatores comportamentais na propensão ao endividamento dos servidores da Universidade Federal de Santa Maria, verificaram que os servidores possuem um comportamento mais conservador em relação ao risco financeiro, uma vez que preferem uma situação de estabilidade e que $69 \%$ possuem a maior parte do patrimônio investida em imóveis. Por conseguinte, a pesquisa demonstrou que mais da metade dos respondentes $(58,8 \%)$ gastam menos do que ganham e 92,9\% não possuem dívidas em atraso.

Quanto a análise de educação financeira dos servidores, percebeu-se que o maior percentual dos entrevistados, $46 \%$, possui um nível alto de conhecimento. O estudo não apurou diferenças no nível de educação financeira em relação às variáveis gênero, escolaridade, estado civil, cargo e renda familiar líquida. Por fim, Flores, Vieira e Coronel (2012) concluíram que devido ao comportamento mais conservador, aqueles servidores apresentam baixa propensão ao endividamento.

Esta mesma concepção foi pesquisada por Silva, Silva Neto e Araújo (2017). Os autores buscaram relacionar a educação financeira com os hábitos de consumo, investimentos e a percepção de riscos de servidores públicos da Seção Judiciária da Justiça Federal na Paraíba, onde destacaram que os servidores possuem baixo nível de conhecimento em educação financeira, apontando a necessidade de implantação de um programa institucional, a fim de melhorar a qualidade de vida dos servidores.

Outro aspecto constatado na pesquisa, foi o de que aqueles que possuem menor grau de instrução gastam menos e consequentemente possuem menos dívidas. Observou-se também que, as mulheres apresentaram maior controle financeiro e menos gastos, em relação aos homens. A idade também foi fator de análise e demonstrou que os mais velhos possuem maiores dificuldades em gerir suas finanças. Esses resultados contrariam diversos estudos realizados anteriormente (OCDE, 2005; LUSARDI; MITCHELL, 2006; POTRICH; VIEIRA; CERETTA, 2014; POTRICH; VIEIRA; KIRCH, 2015).

Já no quarto manuscrito, elaborado por Medeiros e Lopes (2014), o objetivo foi verificar o comportamento dos alunos do curso de Ciências Contábeis de uma IES em Santa Maria - RS, onde a maioria dos entrevistados possui entre 18 a 25 anos. Constatou-se que grande parte dos alunos afirmou gastar menos do que ganham e planejam seus gastos pessoais. Houve variação quanto ao gênero nos aspectos gastos pessoais e poupança, pois os homens possuem um cuidado maior com essas questões. O estudo também constatou que há predomínio entre os alunos da 
consciência dos rendimentos e gestão das finanças pessoais e que grande parte costuma pagar suas compras à vista.

Oliveira e Silva et al. (2017) também abordaram comportamento financeiro dos indivíduos. Os autores combinaram a amostra, constituída por servidores públicos e estudantes de ensino superior e pós-graduação do estado do Rio de Janeiro. A pesquisa compreendeu sete aspectos: alfabetização financeira, educação financeira, perfil de risco do investidor, taxa de poupança, propensão ao endividamento, religiosidade e variáveis socioeconômicas e demográficas. Foram aplicados 300 questionários que resultou na maioria dos respondentes jovens, entre 23 e 29 anos; com renda mensal acima da média brasileira e 90\% da amostra composta de pessoas com nível superior ou pós-graduação. Quanto ao quesito gênero, 50,99\% eram mulheres e $49,01 \%$ homens.

A proposta inicial dos autores foi indicar diferenças conceituais entre alfabetização e educação financeira, a qual foi debatida no artigo e apresentada ao final, em que os autores afirmam que há estreita relação entre tais indicadores, já que a alfabetização financeira é descrita, com base na Organização para Cooperação e Desenvolvimento Econômico (OCDE, 2011), como um conjunto de consciência, conhecimento, habilidade, atitude e comportamento que dá ao indivíduo possibilidade de tomar decisões financeiras mais inteligentes.

Os autores concluíram que o "simples conhecimento sobre finanças pessoais não é o único requisito para que o indivíduo seja alfabetizado financeiramente" (OLIVEIRA SILVA et al., 2017, p. 17). Contudo, observou-se que a variável escolaridade não se mostrou significativa no índice de educação financeira, apenas no nível autodeclarado pelo indivíduo. A única variável estatisticamente significativa nas três dimensões apuradas, segundo os autores, é a poupança.

Osinski et al. (2013) concluíram em sua pesquisa - conduzida com um questionário aplicado em sites institucionais da Universidade Federal de Santa Catarina (UFSC) - que os homens costumam fazer mais orçamentos do que as mulheres e que os jovens planejam mais sua vida no âmbito pessoal do que os mais velhos. Um resultado que merece destaque é o fato de os doutores, que correspondem a $20 \%$ do total de respondentes, apresentaram o menor percentual de utilização do planejamento pessoal.

O último artigo desta categoria, elaborado por Costa e Miranda (2013), ilustra uma investigação quanto a influência da educação financeira na taxa de poupança escolhida pelos brasileiros e a partir disso foi elaborado o índice de educação financeira - IEF, que varia de zero a oito, onde oito representa o nível mais alto e zero a ausência de conhecimento financeiro. A pesquisa foi aplicada a 345 pessoas que responderam o questionário online. Os autores verificaram que o nível de escolaridade não influencia a taxa de poupança. Contudo, "o nível de educação financeira influencia diretamente na decisão de quanto poupar dos indivíduos" 
(COSTA; MIRANDA, 2013, p. 14). O fator idade também não se configura como fator explicativo para a escolha da taxa de poupança. Entretanto, segundo os autores, a cada ano acrescentado na idade, a pessoa poupa em média $-0,37$ pontos percentuais. Também, as pessoas que se declararam como pretas, "poupam, em média, -7,23 pontos percentuais a menos que pessoas que se dizem brancas" (p.11). Corroborando com outras pesquisas, como a que foi conduzida por Osinski et al. (2013), os resultados do estudo proposto por Costa e Miranda (2013) afirmam que os homens poupam mais que as mulheres.

O Quadro 3 apresenta os principais resultados das variáveis analisada em cada estudo, nesta categoria.

Quadro 3 - Resumo das variáveis analisadas.

\begin{tabular}{|c|c|c|c|}
\hline Estudo & Amostra & Variáveis Analisadas & Resultados \\
\hline \multirow[t]{3}{*}{$\begin{array}{l}\text { Silva; Silva Neto; } \\
\text { Araújo, } 2017 .\end{array}$} & \multirow[t]{3}{*}{ Servidores públicos. } & Grau de instrução & $\begin{array}{c}\text { Menor grau de instrução menor propensão ao } \\
\text { endividamento. }\end{array}$ \\
\hline & & Gênero & $\begin{array}{l}\text { As mulheres possuem melhor controle } \\
\text { financeiro e gastam menos. }\end{array}$ \\
\hline & & Idade & $\begin{array}{c}\text { Os mais velhos possuem maiores dificuldades } \\
\text { em gerir suas finanças. }\end{array}$ \\
\hline \multirow[t]{2}{*}{$\begin{array}{l}\text { Flores; Vieira; } \\
\text { Coronel, } 2012 .\end{array}$} & \multirow[t]{2}{*}{ Servidores públicos. } & Comportamento & $\begin{array}{l}\text { São mais conservadores, portanto, apresentam } \\
\text { baixa propensão ao endividamento. }\end{array}$ \\
\hline & & $\begin{array}{l}\text { Gênero, escolaridade, } \\
\text { estado civil, cargo e } \\
\text { renda familiar }\end{array}$ & $\begin{array}{l}\text { Não foram apuradas diferenças entre essas } \\
\text { variáveis em relação ao nível de educação } \\
\text { financeira. }\end{array}$ \\
\hline $\begin{array}{l}\text { Medeiros; Lopes, } \\
2014 .\end{array}$ & $\begin{array}{l}\text { Estudantes do curso } \\
\text { de ciências } \\
\text { contábeis. }\end{array}$ & Gênero & $\begin{array}{l}\text { Homens planejam mais seus gastos e poupam } \\
\text { mais. }\end{array}$ \\
\hline $\begin{array}{l}\text { Oliveira Silva et } \\
\text { al., } 2017 .\end{array}$ & $\begin{array}{l}\text { Servidores públicos } \\
\text { e estudantes de } \\
\text { ensino superior e } \\
\text { pós-graduação do } \\
\text { estado do Rio de } \\
\text { Janeiro. }\end{array}$ & Escolaridade & $\begin{array}{l}\text { Não interferiu no nível de alfabetização } \\
\text { financeira, apenas no nível de alfabetização } \\
\text { financeira autodeclarada. }\end{array}$ \\
\hline \multirow[t]{3}{*}{$\begin{array}{l}\text { Osinski et al., } \\
2013 .\end{array}$} & \multirow{3}{*}{$\begin{array}{l}\text { Servidores públicos } \\
\text { e estudantes } \\
\text { universitários. }\end{array}$} & Gênero & $\begin{array}{l}\text { Os homens costumam fazer mais orçamentos } \\
\text { do que as mulheres. }\end{array}$ \\
\hline & & Idade & Os jovens planejam mais sua vida pessoal. \\
\hline & & Escolaridade & $\begin{array}{l}\text { Os doutores utilizam menos o planejamento } \\
\text { pessoal. }\end{array}$ \\
\hline \multirow{4}{*}{$\begin{array}{l}\text { Costa; Miranda, } \\
2013 .\end{array}$} & \multirow[t]{4}{*}{ Não específica. } & Escolaridade & Não influencia a taxa de poupança escolhida. \\
\hline & & Idade & $\begin{array}{c}\text { Não influencia a taxa de poupança escolhida. } \\
\text { Contudo, quanto mais velho menor a } \\
\text { poupança. }\end{array}$ \\
\hline & & Raça & $\begin{array}{l}\text { As pessoas que se declararam como pretas } \\
\text { poupam menos. }\end{array}$ \\
\hline & & Gênero & Homens poupam mais. \\
\hline
\end{tabular}

Fonte: as autoras.

Observa-se a partir do Quadro 3 que os resultados dos estudos não são unânimes para nenhuma das variáveis investigadas sobre o perfil dos indivíduos, no entanto algumas questões podem ser destacadas: i) gênero e idade são as variáveis mais investigadas nos estudos, sendo que a maioria dos estudos indicam que os homens poupam e/ou planejam mais que as mulheres 
(MEDEIROS; LOPES, 2014; COSTA; MIRANDA, 2013; OSINSKI et al., 2013) e; ii) pessoas mais velhas tendem a ter mais dificuldades para poupar que os mais jovens (SILVA; SILVA NETO; ARAÚJO, 2017; MEDEIROS; LOPES, 2014; COSTA; MIRANDA, 2013; OSINSKI et al., 2013).

A segunda categoria proposta nesta revisão integrativa é comportamento dos inadimplentes, e contempla o agrupamento de dois (2) artigos. O primeiro artigo desta categoria, elaborado por Campara et al. (2016, p.1), explana "os antecedentes e os consequentes do endividamento e quais as estratégias adotadas pelos indivíduos para tornar-se adimplentes, considerando os consequentes da dívida os fatores financeiros, pessoais e sociais”. A pesquisa foi realizada no Clube de Dirigentes Lojistas (CDL) de Santa Maria - RS, pois era o ambiente que favorecia o acesso às pessoas que estavam com seu nome vinculado ao Serviço Central de Proteção ao Crédito (SCPC).

Quanto aos antecedentes da inadimplência, a pesquisa revelou que a ausência de planejamento financeiro foi um dos motivos para 4 dos 14 entrevistados, sendo que desses, 2 apresentam características de consumistas compulsivos. A dívida passiva também foi apontada como um fator, onde se encontram $40 \%$ dos inadimplentes, que ocorre quando a pessoa empresta seu nome para outra pessoa. O desemprego e a cobrança de contas indevidas foram os outros fatores apurados pelos entrevistados.

No que tange às consequências da inadimplência, destacam-se: a exclusão do sistema de crédito, que pode acarretar em exclusão social, onde a pessoa se sente inferior aos demais. Preocupação constante, desconforto, vergonha, mágoa, constrangimento, angústia e problemas conjugais também foram citados pelos entrevistados. Já as estratégias para tornar-se adimplentes, foram: renegociação de dívidas, trabalhar mais, planejar-se, definir prioridades e juntar dinheiro. Por fim, as autoras destacam a importância de cursos ou oficinas que discutam aspectos de finanças pessoais, consumismo e orçamento das despesas mensais (CAMPARA et al., 2016).

O segundo e último artigo, intitulado "Devo, não nego, pago quando puder: uma análise dos antecedentes do endividamento do consumidor", elaborado por Figueira e Pereira (2014), analisa os fatores condicionantes do endividamento do consumidor. A pesquisa investigou os constructos atitude frente ao dinheiro, atitude com cartão de crédito, autocontrole, compra compulsiva, compra impulsiva e propensão ao endividamento. A amostra compreendeu 301 pessoas, que resultou em maioria jovem (71,70\%), entre 19 a 30 anos; solteiros $(67,8 \%)$; do gênero feminino $(54,2 \%) ; 43,9 \%$ possuíam pós-graduação e 55,50\% afirmaram possuir uma renda média mensal superior a $\mathrm{R} \$ 6.000,00$. Possuem cartão de crédito (90\%) e compram menos do que as pessoas próximas a eles $(54,80 \%)$. O constructo 'atitude frente ao dinheiro' foi analisado por meio de três dimensões: poder e prestígio, sensibilidade a preço e ansiedade. 
Os resultados da pesquisa apontaram que poder e prestígio não influenciam positivamente a propensão ao endividamento, apenas na compra compulsiva. Ou seja, as pessoas que usam o dinheiro para obter poder e prestígio perante os demais, são prováveis consumidores compulsivos.

Também ficou constatado que, o fator ansiedade influencia de maneira positiva a compra compulsiva, que os consumidores que possuem ansiedade em gastar são propensos a serem compradores compulsivos e que a compra compulsiva influencia positivamente a propensão ao endividamento. Quanto ao cartão de crédito, a pesquisa revelou que há influência positiva da atitude com cartão de crédito na compra compulsiva, assim como na compulsão por compra e no prazer na compra. Do mesmo modo, concluiu-se que se o indivíduo não possuir um bom autocontrole, ele terá maior propensão a comprar compulsivamente. Por fim, Figueira e Pereira (2014) concluem que a pesquisa confirmou a ideia de que a propensão ao endividamento é afetada diretamente pela atitude com o cartão de crédito.

A terceira categoria, mensuração do conhecimento financeiro, foi atribuída aos artigos que investigaram nível de conhecimento ou alfabetização financeira dos indivíduos. Nesta categoria, estão inclusos quatro (4) artigos. O primeiro manuscrito (VIEIRA et al., 2017) objetivou medir o nível de conhecimento financeiro dos alunos, antes e depois da aplicação do curso de educação financeira para jovens de escolas públicas de ensino fundamental, do município de Santa Maria-Rio Grande do Sul.

Os resultados apontaram que o curso contribuiu para o aumento do conhecimento financeiro dos estudantes, visto que antes dele a média de acertos obtida antes do curso foi de 3,74 e depois, alcançou-se a média de 4,41. Ainda, observou-se que 69,20\% dos estudantes disseram que os pais já haviam comentado sobre como lidar com dinheiro. Este dado revela, de acordo com os autores, que a educação financeira é um tema mais abordado em casa do que na escola.

O segundo artigo (POTRICH, VIEIRA, CERETTA, 2013) desta categoria, buscou verificar se os estudantes de universidades públicas e privadas da cidade de Santa Maria - RS são alfabetizados financeiramente e se a alfabetização é afetada por variáveis socioeconômicas e demográficas. $\mathrm{O}$ índice de conhecimento financeiro dos estudantes variou de 0 a 3,0, conforme classificação proposta por Chen e Volpe (1998).

Ao analisar o indicador comportamento financeiro dos universitários, os autores verificaram que em média, os participantes da pesquisa apresentam comportamento financeiro adequado. Os melhores resultados deste indicador foram apresentados nas questões que tratavam de consumo planejado e utilização de crédito, com médias respectivas de 3,994 e 3,819. O fator 
gestão financeira apresentou média de 3,598, o que representa que os estudantes se preocupam com o cumprimento de seus compromissos financeiros, pois costumam pagar suas contas em dia.

A partir dessas informações coletadas pela escala de conhecimento proposta no estudo, a média do conhecimento financeiro básico resultou em 0,436 em um nível máximo de 1,0 e no conhecimento financeiro avançado a média foi de 1,034, considerando um nível máximo de 2,0 pontos. O resultado final do indicador conhecimento financeiro total apresentou média de 1,470, o que demonstra que os universitários acertaram apenas $49 \%$ das questões. Segundo os autores este resultado é considerado muito baixo para o nível de escolaridade dos respondentes.

A terceira publicação desta categoria foi desenvolvida com 1.400 pessoas residentes no estado do Rio Grande do Sul e buscou produzir um modelo que explique o nível de alfabetização financeira dos indivíduos a partir de variáveis socioeconômicas e demográficas a partir de três construtores: atitude financeira, comportamento e conhecimento financeiro. Este estudo avaliou os mesmos indicadores analisados no estudo anterior e conta com a autoria de Potrich, Vieira e Kirch (2015).

Para o desenvolvimento da pesquisa os autores formularam 8 (oito) hipóteses que contemplam os seguintes pressupostos (Quadro 4):

Quadro 4 - Hipóteses propostas para a pesquisa e os resultados após validação.

\begin{tabular}{|c|l|c|}
\hline Hipótese & \multicolumn{1}{|c|}{ Pressupostos } & Resultado \\
\hline H1 & $\begin{array}{l}\text { Indivíduos do gênero masculino são mais propensos a integrar o grupo com } \\
\text { maior nível de alfabetização financeira. }\end{array}$ & Validada. \\
\hline H2 & $\begin{array}{l}\text { Indivíduos jovens e idosos são menos propensos a integrar o grupo com } \\
\text { maior nível de alfabetização financeira. }\end{array}$ & Rejeitada. \\
\hline H3 & $\begin{array}{l}\text { Indivíduos casados são mais propensos a integrar o grupo com maior nível de } \\
\text { alfabetização financeira. }\end{array}$ & Validada. \\
\hline H4 & $\begin{array}{l}\text { Indivíduos com dependentes são menos propensos a integrar o grupo com } \\
\text { maior nível de alfabetização financeira. }\end{array}$ & Rejeitada. \\
\hline H5 & $\begin{array}{l}\text { Indivíduos com ocupação são mais propensos a integrar o grupo com maior } \\
\text { nível de alfabetização financeira. }\end{array}$ & Validada. \\
\hline H6 & $\begin{array}{l}\text { Nível de escolaridade e nível e alfabetização financeira possuem relação } \\
\text { positiva direta. }\end{array}$ & $\begin{array}{c}\text { Rejeitada. } \\
\text { relação positiva direta. }\end{array}$ \\
\hline H7 & $\begin{array}{l}\text { Nível de renda própria e familiar e nível de alfabetização financeira possuem } \\
\text { relação positiva direta. }\end{array}$ & Validada. \\
\hline H8
\end{tabular}

Fonte: Adaptado de Potrich, Vieira e Kirch, 2015.

Além dos resultados evidenciados no Quadro 4, destaca-se a partir da pesquisa que as variáveis que mais impactam positivamente na alfabetização financeira são: formação, ocupação, gênero e renda.

Roquete, Laureano e Botelho (2014) avaliaram o nível de conhecimento financeiro percepcionado e real, de estudantes universitários portugueses a respeito do crédito e também apreciaram os possíveis condicionantes destes resultados, seguindo a classificação composta por 
Chen e Volpe (1998), sendo que somente 0,8\% dos universitários são considerados detentores de níveis avançados de conhecimento, sendo que $89 \%$ possuem níveis baixos. Por outro lado, o conhecimento que os participantes acreditam possuir revelou-se mediano. Os autores confessam que o conhecimento real tende a aumentar a medida que o conhecimento percepcionado cresce.

Concluiu-se que a região de residência habitual possui relação com o nível de conhecimento e que os estudantes matriculados em cursos de Ciências Empresariais são mais propensos a possuir maior nível de conhecimento e que essa métrica aumenta à medida que o estudante avança no curso. Outro dado apurado mostrou que os estudantes de tecnologia apresentaram a média mais baixa de respostas corretas.

Os autores finalizam a pesquisa reconhecendo a urgência e a necessidade de elaborar estratégias e programas que minimizem os efeitos do analfabetismo financeiro, como é o caso das mulheres, indivíduos com baixa escolaridade, renda e com dependentes. Como nas pesquisas anteriores (POTRICH, VIEIRA, CERETTA, 2013; POTRICH, VIEIRA, KIRCH, 2015; VIEIRA, et al., 2017), estes também sugeriram a adoção de disciplinas de finanças pessoais em todos os cursos de graduação, independente da área de ensino. Programas educativos voltados para toda a sociedade, com conteúdo e ações específicas para cada grupo de indivíduos também foram citados, além de sugerirem disciplinas e atividades relacionadas igualmente nos níveis iniciais de ensino, pois no longo prazo essas estratégias poderiam tornar as crianças mais conscientes e preparadas para a gestão financeira, bem como reduzir as desigualdades antes dos indivíduos se tornaram adultos.

As considerações dos autores reforçam os estudos anteriores desta categoria, ao afirmarem que é necessário tomar medidas para reduzir as insuficiências apontadas na pesquisa. Outra constatação feita foi a importância de promover a educação financeira na população universitária e adulta, além dos níveis iniciais de educação que já começaram a ser atendidos por alguns governos. O Quadro 5 expõe o resumo das variáveis analisadas nos manuscritos desta categoria. 
FAZ CIÊNCIA, VOL. 22, N. 35, JAN/JUN DE 2020 - P. 139-159

Quadro 5 - Resumo das variáveis analisadas.

\begin{tabular}{|c|c|c|c|c|}
\hline Estudo & Objetivo & Amostra & $\begin{array}{l}\text { Variáveis } \\
\text { Analisadas }\end{array}$ & Resultados \\
\hline \multirow[t]{6}{*}{$\begin{array}{l}\text { Potrich, Vieira, } \\
\text { Ceretta, } 2013 .\end{array}$} & \multirow{6}{*}{$\begin{array}{c}\text { Verificar se os } \\
\text { estudantes universitários } \\
\text { são alfabetizados } \\
\text { financeiramente e se a } \\
\text { alfabetização é afetada } \\
\text { por variáveis } \\
\text { socioeconômicas e } \\
\text { demográficas. }\end{array}$} & \multirow[t]{6}{*}{$\begin{array}{c}\text { Estudantes } \\
\text { universitários }\end{array}$} & Gênero & $\begin{array}{l}\text { Os homens possuem melhores } \\
\text { comportamentos financeiros, } \\
\text { compreendem melhor os } \\
\text { conceitos financeiros e possuem } \\
\text { maior nível de alfabetização } \\
\text { financeira. } \\
\end{array}$ \\
\hline & & & Raça & $\begin{array}{l}\text { Os declarados brancos possuem } \\
\text { melhores comportamentos } \\
\text { financeiros e maiores níveis } \\
\text { alfabetização financeira. }\end{array}$ \\
\hline & & & Ocupação & $\begin{array}{l}\text { Indivíduos com ocupação } \\
\text { possuem melhores } \\
\text { comportamentos financeiros, } \\
\text { compreendem melhor os } \\
\text { conceitos financeiros e possuem } \\
\text { maior nível de alfabetização } \\
\text { financeira } \\
\end{array}$ \\
\hline & & & Formação & $\begin{array}{c}\text { Alunos com disciplinas de } \\
\text { finanças pessoais e de mercado } \\
\text { possuem melhor comportamento, } \\
\text { conhecimento, atitude financeira } \\
\text { e alfabetização financeira. }\end{array}$ \\
\hline & & & Idade & $\begin{array}{l}\text { Os mais velhos apresentam } \\
\text { melhores níveis de conhecimento } \\
\text { financeiro e de alfabetização } \\
\text { financeira. }\end{array}$ \\
\hline & & & Renda & $\begin{array}{l}\text { Quanto maior a renda maior o } \\
\text { conhecimento financeiro e o nível } \\
\text { de alfabetização financeira. }\end{array}$ \\
\hline \multirow[t]{4}{*}{$\begin{array}{c}\text { Roquete, } \\
\text { Laureano, } \\
\text { Botelho, 2014. }\end{array}$} & \multirow{4}{*}{$\begin{array}{l}\text { Avaliar o nível de } \\
\text { conhecimento financeiro } \\
\text { percepcionado e real de } \\
\text { estudantes universitários } \\
\text { a respeito do crédito. }\end{array}$} & \multirow[t]{4}{*}{$\begin{array}{l}\text { Estudantes } \\
\text { universitários } \\
\text { de Lisboa }\end{array}$} & Região & $\begin{array}{l}\text { A região de residência pode } \\
\text { influenciar no nível de } \\
\text { conhecimento financeiro. }\end{array}$ \\
\hline & & & $\begin{array}{l}\text { Composição } \\
\text { familiar }\end{array}$ & $\begin{array}{c}\text { Os estudantes que residem } \\
\text { sozinhos ou fora da casa dos pais } \\
\text { possuem maiores conhecimentos } \\
\text { financeiros. }\end{array}$ \\
\hline & & & Formação & $\begin{array}{l}\text { Estudantes dos cursos de ciências } \\
\text { empresariais são mais propensos } \\
\text { a possuírem maiores } \\
\text { conhecimentos; } \\
\text { Quanto mais avançado no curso } \\
\text { melhor o conhecimento. }\end{array}$ \\
\hline & & & Renda & $\begin{array}{l}\text { Quanto maior a renda maior o } \\
\text { nível de conhecimento financeiro. }\end{array}$ \\
\hline \multirow[t]{3}{*}{$\begin{array}{l}\text { Potrich, Vieira, } \\
\text { Kirch, } 2015 .\end{array}$} & & & Gênero & $\begin{array}{c}\text { Homens possuem maior nível de } \\
\text { alfabetização financeira }\end{array}$ \\
\hline & & & Renda & $\begin{array}{l}\text { Quanto maior a renda maior o } \\
\text { nível de alfabetização financeira.. }\end{array}$ \\
\hline & & & Escolaridade & $\begin{array}{l}\text { Quanto maior o nível de } \\
\text { escolaridade maior o nível de } \\
\text { alfabetização financeira. }\end{array}$ \\
\hline
\end{tabular}

Fonte: Própria, 2017.

A análise do Quadro 5 corrobora com os estudos que afirma que homens tendem a ter maior alfabetização financeira do que as mulheres, que os mais velhos apresentam menor nível de conhecimento financeiro, e talvez por isso poupam menos que os mais jovens. Observa-se 
nestes estudos e nos demais já destacados, a importância da inclusão da educação financeira como ferramenta para minimizar tais distorções presentes nas variáveis: gênero, renda, idade, raça e ocupação. Incluir estes temas nas grades curriculares do ensino médio e das universidades pode ser uma saída, conforme destacam os autores (OLIVEIRA SILVA et al., 2017; ROQUETE; LAUREANO; BOTELHO, 2014; MEDEIROS; LOPES, 2014. POTRICH; VIEIRA; CERETTA, 2013).

A quarta e última categoria da revisão integrativa, educação financeira na infância, é contemplada por quatro (4) artigos e todos em algum momento abordam a proposta da educação financeira durante a infância. O primeiro artigo, elaborado por Cunha e Laudares (2017) abordou a educação financeira por meio de atividades que enfocaram conceitos e cálculos da matemática financeira, com questões imersas em valores socioeconômicos. A amostra da pesquisa foi composta por estudantes do ensino médio que trabalharam com as atividades de funções e progressões do conteúdo programático de matemática condizente com o nível de ensino.

Nesta pesquisa o aluno teve papel de questionador, que após a leitura dos textos propostos deveria relacionar o que havia lido e expor algumas noções de cunho econômicofinanceiro. A relação entre juros compostos e a função exponencial não foi muito bem estabelecida pelos alunos, o que segundo os autores, demonstra a forma discreta de abordar esses assuntos no meio escolar.

Outra informação obtida nesta questão, foi o fato de que os alunos conhecem e decoram a fórmula, porém não sabem o significado das variáveis e muito menos conseguem deduzir a relação entre elas. "O ensino baseado em memorização de fórmulas é inútil para lidar com situações reais simples, como as que utilizamos nos itens citados" (CUNHA, LAUDARES, 2017, $\mathrm{p}$ 13). Ao final da pesquisa, os autores consideraram que atividades como estas que foram propostas podem contribuir para a inclusão dos estudantes na matemática financeira, melhorando assim o conhecimento acerca da vida econômico-financeira do brasileiro.

Destefani (2015) abordou a importância da educação financeira na infância, por meio de um estudo de caso realizado com pais de crianças em idade escolar, cursando o período da préescola até o quinto ano do ensino fundamental de escolas públicas e privadas do município de Sinop, estado do Mato Grosso. O objetivo da pesquisa foi constatar se os pais estão empenhados em ensinar seus filhos a trabalhar com o dinheiro e de que maneira essa educação está acontecendo.

A pesquisa apurou que apesar da discrepância entre as rendas e mesmo que algumas famílias possuam condições de proporcionar certas comodidades aos filhos, a maioria dos pais está empenhada em criar filhos consumidores conscientes. Essa preocupação é importante, dada o estímulo ao consumo que é posto aos indivíduos desde sua infância. Contudo, os resultados 
apuraram que os pais ainda acreditam ser muito cedo para iniciar o processo de educação financeira com seus filhos (DESTEFANI, 2015).

O próximo manuscrito aborda a educação financeira a partir de uma proposta didáticopedagógica, em uma turma do $7^{\circ}$ ano do ensino fundamental, de uma escola da rede municipal de ensino do município de Getúlio Vargas, estado do Rio Grande do Sul. O objetivo da pesquisa foi analisar se as interações produzidas no desenvolvimento da proposta didático-pedagógica possibilitam a apropriação de significados dos conteúdos ligados à educação financeira, com vistas à conscientização por parte dos estudantes sobre sua importância e necessidade para a tomada de decisões financeiras conscientes (SCOLARI; GRANDO, 2016).

A atividade mais significativa da proposta foi a elaboração de um orçamento doméstico, baseado nas próprias famílias ou situações fictícias. A pesquisa de produtos que fazem parte de uma cesta básica e a elaboração de um livro sobre a educação financeira também foi proposta aos estudantes ao final da proposta didático-pedagógica.

As autoras observaram que a metodologia proposta, em que os alunos deveriam buscar informações sem a exposição do conteúdo por parte da professora, apresentou certa resistência dos alunos justamente por não estarem habituados a desenvolver atividades desta forma. E que há uma lacuna no processo de ensino-aprendizagem da educação financeira, pois ela não está presente na grade curricular de grande parte das escolas de educação básica. Segundo as autoras, cabe a escola observar a importância de formar pessoas mais conscientes financeiramente.

O último artigo desta categoria foi produzida por Silva e Silva e Escorisa (2017) e teve como objetivo registrar a percepção dos alunos sobre a educação financeira nas escolas. $\mathrm{O}$ estudo foi aplicado por meio de um minicurso com conteúdo introdutório de gestão de finanças pessoais com alunos do ensino fundamental de três escolas do município de Barra das Garças, estado do Mato Grosso, no ano de 2015.

Com a aplicação do questionário e obtenção de feedback do minicurso, os pesquisadores constataram que para $83 \%$ dos alunos o minicurso foi útil para o controle dos gastos. Também observaram que $68 \%$ dos alunos afirmaram que o primeiro contato com o tema foi realizado no minicurso. Nesse sentido, percebe-se que a educação financeira não é muito abordada nas escolas, mas, segundo os autores, a escola possui papel fundamental na conscientização dos jovens estudantes sobre o mercado financeiro e suas armadilhas. Também, de acordo com os autores, cabe aos pais um papel importante neste processo, uma vez que os pais influenciam a alfabetização financeira dos filhos.

Do total de alunos pesquisados, 57\% dos alunos afirmaram que dialogaram com os familiares o aprendizado obtido no minicurso e cerca de $34 \%$ do total dos alunos disseram que a 
família mudou de alguma maneira o modo como gerenciavam as finanças, como o hábito de poupar, de controlar os gastos e a pesquisa de preços antes das compras.

Em suma, os artigos desta categoria consideram a importância da educação financeira na infância, que pode ser abordada em programas curriculares do ensino básico e ainda defendem os ganhos individuais e coletivos dessas ações, pois por meio da educação financeira, as pessoas possuem melhores condições de administrarem suas vidas com maior eficiência, além de evoluírem cognitivamente. Além disso, no entendimento dos autores, todos os envolvidos devem participar desse processo de ensino-aprendizagem, haja vista que nem todos os pais possuem condições para ensinar finanças aos jovens e o despreparo dos professores para adotar métodos interativos.

\section{Considerações Finais}

A partir dos estudos analisados, observa-se que o tema finanças pessoais desperta interesse dos pesquisadores, principalmente quando correlacionado ao nível de conhecimento financeiro dos indivíduos, visto que a temática importa não só a instituições de ensino, mas também ao Estado, que se submete a arrecadação, o que decorre da conjuntura econômica e financeira dos particulares e substancialmente do todo.

Quanto ao ano de publicação, destacaram-se os anos de 2013 e 2017, oriundos majoritariamente do descritor conhecimento financeiro. Igualmente, com relação a categorização dos estudos, a segunda categoria proposta, perfil e variáveis em finanças pessoais, apreciou 7 (sete) manuscritos, o que representa a maioria (41\%) dos estudos. A partir da integração dos manuscritos pode-se auferir que o comportamento dos indivíduos com relação a dívida está em muitos dos estudos correlacionado a seguintes variáveis: gênero, renda, escolaridade, formação e raça. Observa-se, a partir da literatura que os indivíduos do gênero masculino, brancos, com maior nível de escolaridade e renda e que possuem em sua formação disciplinas de finanças são os possíveis detentores de maior nível de conhecimento financeiro.

Por fim, salienta-se a importância da temática de finanças pessoais como tema transversal, tanto nos ensinos fundamental e médio, quanto no meio universitário. Muitos autores reforçam a necessidade de implantação de uma política nacional de educação financeira para crianças, jovens e adultos, a fim de que os indicadores de inadimplência e endividamento sejam reduzidos no Brasil.

\section{Referências}

CAMPARA, Jéssica Pulino; VIEIRA, Kelmara Mendes; COSTA, Vânia Medianeira Flores Costa; FRAGA, Luana dos Santos. O Dilema dos Inadimplentes: Antecedentes e Consequentes do 
"nome sujo". REMark, v. 15, n. 1, p. 71, 2016. Disponível em: <10.5585/remark.v15i1.2941 >. Acesso em: 22 nov. 2017.

CHEN, Haiyang; VOLPE, Ronald P. An Analysis of Personal Financial Literacy Among College Students. 1998.

Disponível em: <http://citeseerx.ist.psu.edu/viewdoc/download?doi=10.1.1.392.4650\&rep=rep1\&type=pdf >. Acesso em 20 ago. 2018.

CLAUDINO, Lucas Paravizo; NUNES, Murilo Barbosa; SILVA, Fernanda Cristana da. Finanças pessoais: um estudo de caso com servidores públicos. In: SEMINÁRIOS EM ADMINISTRAÇÃO. Anais dos Seminários em Administração - SemeAd. 2009, São Paulo, 2009. Disponível em: http://sistema.semead.com.br/12semead/resultado/trabalhosPDF/724.pdf. Acesso em: 08 set. 2017.

COSTA, Cristiano Machado; MIRANDA, Cléber José. Educação Financeira e taxa de poupança no Brasil. Revista de Gestão, Finanças e Contabilidade, v. 3, n. 3, p. 57, 2013. Disponível em: <https://doaj.org/article/df9f9114ac894e26afbca2b7a00f34c0>. Acesso em: 22 nov. 2017.

CUNHA, Clístenes Lopes da; LAUDARES, João Bosco. Resolução de Problemas na Matemática Financeira para Tratamento de Questões da Educação Financeira no Ensino Médio. Boletim de Educação Matemática, v. 31, n. 58, 2017. Disponível em: <http://dx.doi.org/10.1590/19804415v31n58a07>. Acesso em: 22 nov. 2017.

SILVA E SILVA, Felipe Deodato da; ESCORISA, Natália Valadão. Percepções de jovens estudantes sobre a educação financeira: um estudo em Barra do Garças-MT-Perceptions of young students on the financial education: a study in Barra do Garças-MT. Educação Matemática Pesquisa, $\quad$ v. $19, \quad$ n. $1, \quad 2017 . \quad$ Disponível <https://revistas.pucsp.br/index.php/emp/article/view/31177>. Acesso em: 23 ago. 2017.

SILVA, Jucyara Gomes da; NETO, Odilon Saturnino Silva; CUNHA ARAÚJO, Rebeca Cordeiro da. Educação Financeira de Servidores Públicos: Hábitos de Consumo, Investimento e Percepção de Risco. Revista Evidenciação Contábil \& Finanças, v. 5, n. 2, p. 104-120, 2017. Disponível em: <10.18405/recfin20170207>. Acesso em: 22 nov. 2017.

DE OLIVEIRA SILVA, Guilherme; SILVA, Antônio Carlos da; VIEIRA, Paulo Roberto da Costa; DESIDERATI, Michele do Carmo; DAS NEVES, Myrian Beatriz Eiras. Alfabetização financeir versus educação financeira: um estudo do comportamento de variáveis socioeconômicas e demográficas. Revista de Gestão, Finanças e Contabilidade, v. 7, n. 3, p. 279-298, 2017. Disponível em: <http://www.revistas.uneb.br/index.php/financ/article/view/3726/2444>. Acesso em 02 out. 2017.

DESTEFANI, Sonia Maria. Educação financeira na infância. Eventos Pedagógicos, v. 6, n. 4, p. 274-282 2015.

Disponível

em:

<http://sinop.unemat.br/projetos/revista/index.php/eventos/article/view/2012>. Acesso em: 22 nov. 2017.

FERNANDES, André Henrique de Souza; CANDIDO, João Gremmelmaier. Educação financeira e nível do endividamento: relato de pesquisa entre os estudantes de uma instituição de ensino da cidade de São Paulo. Revista Eletrônica Gestão e Serviços, v. 5, n. 2, p. 894-913, 2014. Disponivel em: <https://www.metodista.br/revistas/revistasims/index.php/REGS/article/view/4868>. Acesso em: 22 nov. 2017.

FIGUEIRA, Rebeca Formiga; PEREIRA, Rita de Cassia de Faria. Devo, não nego, pago quando puder: uma análise dos antecedentes do endividamento do consumidor. Revista Brasileira de Marketing, $\quad$ v. $13, \quad$ n. $\quad 5, \quad 2014 . \quad$ Disponível em: <http://www.redalyc.org/html/4717/471747343009/>. Acesso em: 22 nov. 2017. 
FLORES, Silvia Amélia Mendonça; VIEIRA, Kelmara Mendes; CORONEL, Daniel Arruda. Influência de fatores comportamentais na propensão ao endividamento. Revista de Administração FACES Journal, v. 12, n. 2, 2013. Disponível em: <https://doaj.org/article/fea4585f23894bffa209aee6098ec7bf>. Acesso em: 22 nov. 2017

LUCCI, Cintia Retz; ZERRENER, Sabrina Arruda; VERRONE, Marco Antonio Guimarães; SANTOS, Sérgio Cirpriano A influência da educação financeira nas decisões de consumo e investimento dos indivíduos. In: SEMINÁRIOS EM ADMINISTRAÇÃO, 9., 2006, São Paulo. Anais dos Seminários em Administração - SemeAd. Disponível em: <http://sistema.semead.com.br/9semead/resultado_semead/trabalhosPDF/266.pdf >. Acesso em: 03 set. 2017.

LUSARDI, Annamaria; MITCHELL, Olivia S. Financial literacy and retirement prepared-ness: Evidence and implications for financial education. Disponível em: < https://www.dartmouth.edu/ alusardi/Papers/Financial_Literacy.pdf $>$. Acesso em: 15 nov. 2017.

MATTA, Rodrigo Octávio Beton. Oferta e demanda de informação financeira pessoal: o Programa de Educação Financeira do Banco Central do Brasil e os universitários do Distrito Federal. Brasília: UNB, 2007. 214p. Dissertação (Mestrado em Ciência da Informação). Disponível em:

<http://repositorio.unb.br/bitstream/10482/5293/1/2007\%20Rodrigo\%20Oct\%C3\%A1vio\%20Be ton\%20Matta.pdf>. Acesso em: 01 out. 2017

MEDEIROS, Flaviani Souto Bolzan; LOPES, Taize de Andrade Machado. Finanças pessoais: um estudo com alunos do Curso de Ciências Contábeis de uma IES privada de Santa MariaRS. Revista Eletrônica de Estratégia \& Negócios, v. 7, n. 2, p. 221-251, 2014. Disponível em: <http://www.portaldeperiodicos.unisul.br/index.php/EeN/article/view/1966>. Acesso em: 22 nov. 2017.

MENDES, Karina Dal Sasso; SILVEIRA, Renata Cristina de Campos Pereira; GALVAO, Cristina Maria. Revisão integrativa: método de pesquisa para a incorporação de evidências na saúde e na enfermagem. Texto contexto - enferm. Florianópolis, v. 17, n. 4, p. 758764, Dec. 2008. Available from <http://dx.doi.org/10.1590/S0104-07072008000400018>. Acesso em: 01 dez. 2017.

MINISTÉRIO DA EDUCAÇÃO (MEC). Base Nacional Comum Curricular. Disponível em: < http://basenacionalcomum.mec.gov.br/images/BNCC_publicacao.pdf> . Acesso em: 02 out. 2017.

Educação Financeira. Disponível em: <
http://portal.mec.gov.br/component/tags/tag/35987-educacao-financeira>. Acesso em 19 out. 2018.

MOREIRA, Romilson; DE CARVALHO, Henrique Levi Freitas Sena. As finanças pessoais dos professores da rede municipal de ensino de campo formoso-Bahia: um estudo na escola José de Anchieta. Revista de Gestão, Finanças e Contabilidade, v. 3, n. 1, p. 122, 2013. Disponível em: <https://doaj.org/article/da714a58270045519fa3ec49bbeb85d7?frbrVersion=4>. Acesso em: 22 nov. 2017.

NUNES, Patrícia. Utilização da Contabilidade no planejamento e controle das finanças pessoais. Disponível em: < http://revista.crcsc.org.br/index.php/CRCSC/article/view/1158>. Acesso em: 08 set. 2017.

OCDED. Recommendation on Principles and Good Practices for Financial Education and Awareness: Recommendation of the council, 2005. Disponível em: <http://www.oecd.org/finance/financial-education/35108560.pdf>. Acesso em: 13 nov. 2017 
OCDED. Adult Financial Literacy Competencies. 2016. Disponível em: < https://www.oecd.org/daf/fin/financial-education/OECD-INFE-International-Survey-of-AdultFinancial-Literacy-Competencies.pdf>. Acesso em: 18 out. 2018.

OLIVATO, H.; SOUZA, PKB d. Endividamento: um estudo preliminar dos fatores contribuintes. Anais do Simpósio de Educação e Encontro científico de Educação da Unisalesiano, 2007.

OSINSKI, Marilei, PEREIRA, Maurício Fernandes; NEIS, Dyogo Felype; NETO, Siqueira de Moraes. Planejamento Estratégico Pessoal: a caminho de um referencial. Revista de Ciências da Administração, v. 15, n. 37, 2013. Disponível em: < http://dx.doi.org/10.5007/21758077.2013v15n37p121>. Acesso em: 22 nov. 2017.

POTRICH, Ani Caroline Grigion; VIEIRA, Kelmara. Mendes; CERETTA, Paulo. Sergio. Nível de alfabetização financeira dos estudantes universitários: afinal, o que é relevante?. Revista Eletrônica de Ciência Administrativa, v. 12, n. 3, p. 314-333, 2013. Disponível em: $<\mathrm{http}$ //www.spell.org.br/documentos/ver/18839/nivel-de-alfabetizacao-financeira-dosestudantes-universitarios — afinal--o-que-e-relevante>. Acesso em: 02 out. 2017.

POTRICH, Ani Carline Grigion; VIEIRA, Kelmara Mendes; PARABONI, Ana Luíza. O que influencia a alfabetização financeira dos estudantes universitários. XII Seminários em Administração, 2013. Disponível em: <http://sistema.semead.com.br/16semead/resultado/trabalhosPDF/375.pdf>. Acesso em: 02 out. 2017.

POTRICH, Ani Caroline Grigion; VIEIRA, Kelmara Mendes; KIRCH, Guilherme. Determinantes da Alfabetização Financeira: Análise da Influência de Variáveis Socioeconômicas e Demográficas. Revista Contabilidade \& Finanças-USP, v. 26, n. 69, p. 362-377, 2015. Disponível em: <http://dx.doi.org/10.1590/1808-057x201501040>. Acesso em: 22 nov. 2017.

ROQUETTE, Inês Ulrica Araújo; LAUREANO, Raul; BOTELHO, Maria do Carmo. Conhecimento financeiro de estudantes universitários na vertente do crédito. Tourism \& Management Studies, v. 10, 2014. Disponível em: <http://www.redalyc.org/html/3887/388743880016/>. Acesso em: 02 dez. 2017

SAITO, André Taue. Uma contribuição ao desenvolvimento da educação em finanças pessoais no Brasil. 2007. Tese de Doutorado. Universidade de São Paulo. Disponível em: < 10.11606/D.12.2007.tde-28012008-141149 >. Acesso em: 23 ago. 2017.

SAVOIA, José Roberto Ferreira; SAITO, André Taue; SANTANA, Flávia de Angelis. Paradigmas da educação financeira no Brasil. Disponível em: < http://www.scielo.br/scielo.php?script=sci_arttext\&pid=S0034-76122007000600006>. $76122007000600006 \&$ lang=pt>. Acesso em: 23 ago. 2017.

SCOLARI, Lidinara Castelli; GRANDO, Neiva Ignês. Educação financeira: uma proposta desenvolvida no ensino fundamental. Educação Matemática Pesquisa, v. 18, n. 2, 2016. Disponível em: <https://revistas.pucsp.br/index.php/emp/article/view/22477>. Acesso em: 22 nov. 2017.

SERASA EXPERIAN. Um em cada cinco inadimplentes no Brasil tem entre 41 e 50 anos, revela Serasa Experian. 2019. Disponível em: https://www.serasaexperian.com.br/sala-de-imprensa/umem-cada-cinco-inadimplentes-no-brasil-tem-entre-41-e-50-anos-revela-serasa-experian>. Acesso em 15 abr. 2020.

TRINDADE, Larissa de Lima. Determinantes da propensão ao endividamento: um estudo nas mulheres da mesorregião centro ocidental rio-grandense. 2009. 101 f. 2009. Tese de Doutorado. Dissertação (Mestrado em Administração)-Programa de Pós-Graduação em Administração, Universidade Federal de Santa Maria-UFSM, Santa Maria. Disponível em: <http://repositorio.ufsm.br/handle/1/4550>. Acesso em: 28 out. 2017. 
VENTURA, Rodrigo. Mudanças no perfil d o consumo no Brasil: Principais Tendências nos próximos 20 anos. MACROPLAN, 2010. Disponível: <http://macroplan.com.br/documentos/artigomacroplan2010817182941.pdf>. Acesso em: 03 set. 2017.

VIEIRA, Kelmara Mendes; FLORES, Silvia Amélia Mendonça; CAMPARA, Jéssica Pulino. Propensão ao endividamento no município de Santa Maria (RS): verificando diferenças em variáveis demográficas e culturais. TPA-Teoria e Prática em Administração, v. 4, n. 2, p. 180-205, 2015.

VIEIRA, Kelmara Mendes, VALCANOVER, Vanessa Martins; BRUTTI, Franciele; TRINDADE, Caroline Rosa; KEGLER, Josiane Júlia. Aprendendo Finanças de Um Jeito Fácil e Divertido: Uma experiência com estudantes de escolas públicas. Revista Ibero-Americana de Estudos em Educação, v. 12, n. esp., p. 845-861, 2017. Disponível em: <http://dx.doi.org/10.21723/riaee.v12.n2.8479>. Acesso em: 22 nov. 2017.

ZERRENNER, Sabrina Arruda. Estudo sobre as razões para o endividamento da população de baixa renda. 2007. Tese de Doutorado. Universidade de São Paulo. Disponível em:<10.11606/D.12.2007.tde-13112007-120236 >. Acesso em: 03 set. 2017.

Recebido em 16/04/2020 - Aprovado em 25/06/2020. 